\title{
Multidetector Computed Tomographic Characterization of a Rare Retroperitoneal Mass in the Left Psoas Compartment
}

\author{
Rochita Venkata Ramanan¹ Elankumaran Krishnan² \\ ${ }^{1}$ Department of Radiology, Apollo Hospitals, Chennai, India \\ 2Department of Hepatobiliary Surgery and Liver Transplantation, \\ Apollo Hospitals, Chennai, India \\ ${ }^{3}$ Department of Pathology, Apollo Hospitals, Chennai, India
}

\author{
Maya Menon ${ }^{3}$ Ponneyinchelvi Shivanandan ${ }^{3}$
}

J Gastrointestinal Abdominal Radiol ISGAR 2018;1:41-55
Abstract
Keywords
- multidetector com- puted tomography
- primary ureteric sarcoma
- retroperitoneal sarcoma
- transitional cell carcinoma
- psoas sarcoma
- psoas space
- retroperitoneum

\begin{abstract}
Address for correspondence Rochita Venkata Ramanan, MD, DNB, DMRD, Apollo Hospitals, No. 34, Srinivasa Murthy Avenue, Off L. B. Road, Adyar, Chennai 600020, Tamil Nadu, India (e-mail: rochitav@gmail.com).
\end{abstract}

\section{Introduction}

Characterization of retroperitoneal disease is an important exercise in the field of cross-sectional imaging. Retroperitoneal soft tissue masses can present challenges in characterization on imaging as significant overlap exists in their appearances. Identifying the structure of origin of soft tissue tumors can be tricky when masses are large and cross boundaries between compartments. Localizing them to the retroperitoneal compartment of origin, characterizing them by their tissue components, and demonstrating their relation to vital structures can be valuable in planning surgery. We present a case of a rare large retroperitoneal mass that presented challenges in diagnosis and demonstrate a step-by-step approach to resolve these.

\section{Case Presentation}

\section{Clinical Details}

A 62-year-old man from West Bengal presented with continuous dull aching nonradiating pain in the left lower quadrant associated with fullness of 3-month duration. His bowel and bladder habits were normal, and he gave no history of loss of appetite or weight or hematuria. He was a known diabetic on treatment with insulin. He gave history of excision of a lump in the left thigh 30 years back, whose details are not available. His general physical examination and electrocardiogram (ECG) were normal.

On clinical examination, a hard mass could be palpated in the left iliac fossa measuring approximately $10 \mathrm{~cm}$. It extended into the left lumbar and umbilical regions with ill-defined margins. His blood workup was normal. An ultrasound (US) examination of the patient done elsewhere revealed left hydroureteronephrosis and an ill-defined mass in the left lumbar and iliac region. A computed tomographic (CT) scan was advised to characterize the mass and assess operability.

\section{Computed Tomographic Scan Procedure}

The CT examination was obtained with the Aquilion One CT system, (Canon, Tokyo, Japan) on the 64-section helical mode.

\section{$10.1055 / \mathrm{s}-0038-1676258$}

License terms

(1) (1) $\Theta \circledast$ 
The patient received intravenous contrast medium of $100 \mathrm{~mL}$ iopromide (Ultravist 370; Schering, Berlin, Germany), which amounted to a dose of $1.3 \mathrm{~mL} / \mathrm{kg}$ body weight at an injection rate of $4 \mathrm{~mL} / \mathrm{s}$. CT images were obtained during the arterial phase using a bolus-tracking method, venous phase using a 70-second delay, and a delayed phase after 10 minutes of contrast medium administration with a $0.5-\mathrm{mm}$ section thickness. The tube voltage was at $120 \mathrm{kVp}$, and tube current was set to automatic, which modulated the dose according to the patient size. The images were analyzed on a dedicated Vitrea workstation (Vital Images, Minnetonka, Minnesota, United States). Multiplanar reconstructions in the coronal, sagittal, and oblique planes were also performed and read in addition to the axial sections.

\section{Case Analysis}

\section{Origin of Mass}

A spherical mass lesion was identified on the left side of the abdomen. It was located predominantly within the left psoas muscle in the midportion of its belly (-Fig. 1). The mass involved the full thickness of the psoas muscle measuring about $10.4 \times 10.0 \mathrm{~cm}$ in cross section through its widest portion. In the craniocaudal dimensions, it measured $12.3 \mathrm{~cm}$ making it fairly spherical in shape. Laterally, the quadratus lumborum muscle was involved (-Fig. 2). However, there was no involvement of the paraspinal muscles. Origins of the psoas muscle as well as its distal belly and the iliopsoas tendon were uninvolved ( $\mathbf{- F i g}$. 3A, B). A fat plane could be found between the psoas and the iliacus muscle suggesting noninvolvement of the iliacus. The oblique abdominal muscles of the lateral abdominal wall were not involved. The mass was well circumscribed and contained within the psoas space. Anteriorly the mass was closely related to the mid segment of the left ureter for a length of $7 \mathrm{~cm}$. No fat plane could be identified between the ureter and anterior surface of the mass establishing that the mass was infiltrating the ureter (-Fig. 4A, B). The ureter did not reveal any anterior displacement as would be expected of a mass arising from the psoas muscle. Instead, it was completely entrapped at the level of the equator of the mass. The mass also appeared to grow for a short length of $1.5 \mathrm{~cm}$ cranially within the lumen of the ureter obstructing it (-Figs. 5A, B, 6A, B). Proximally the ureter and pelvicalyceal system were dilated without

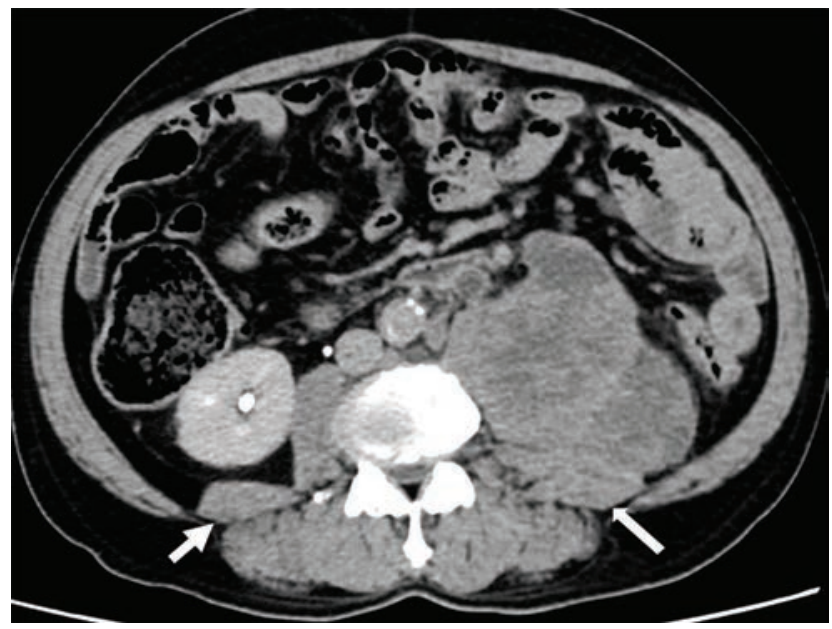

Fig. 2 Axial CT section in delayed phase reveals involvement of the left quadratus lumborum muscle by the mass (thin long arrow). The right normal quadratus lumborum is marked by the short stout arrow.
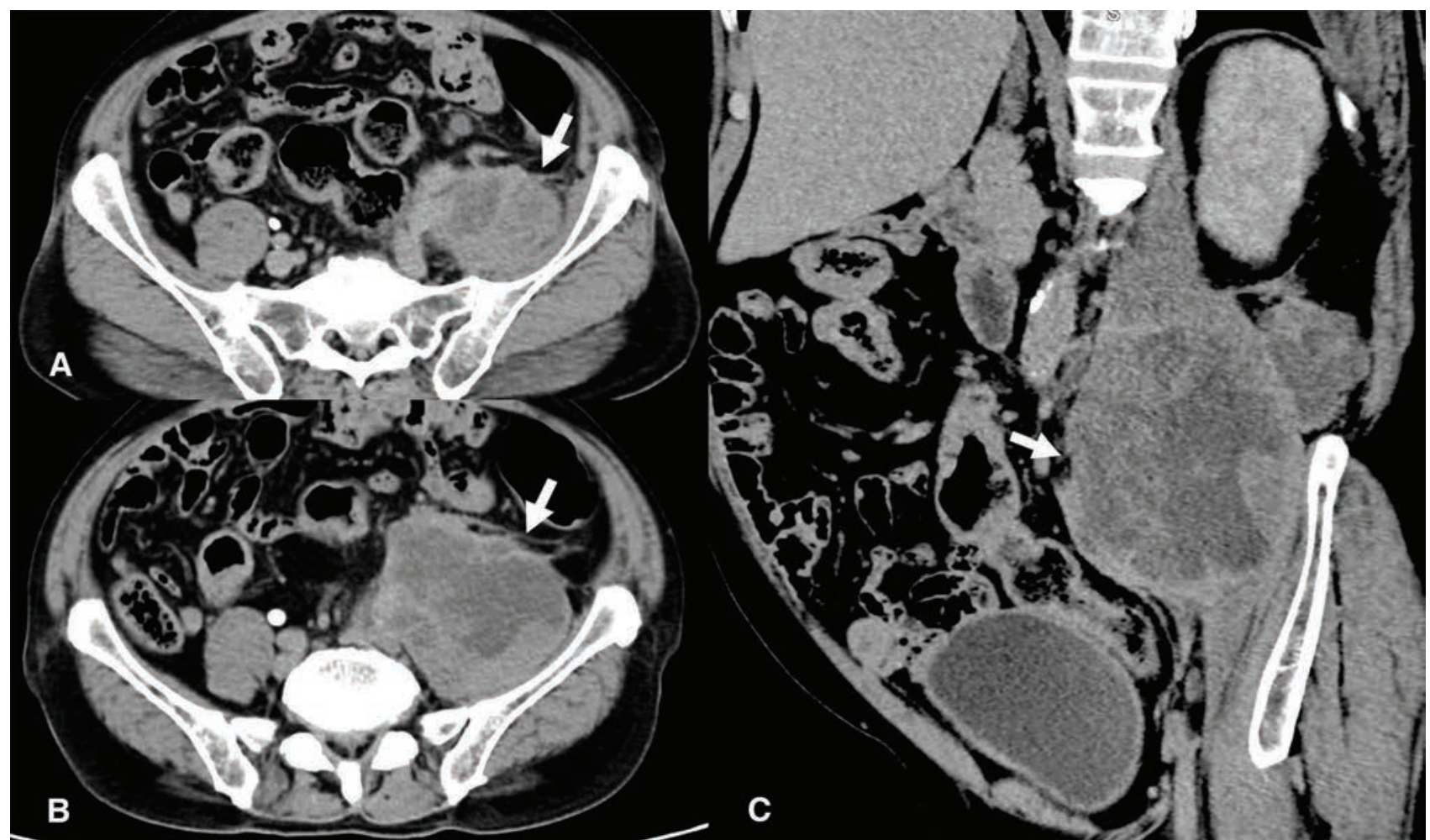

Fig. 1 (A) Lower and (B) higher axial CT sections and (C) oblique sagittal reconstruction in delayed phases show a heterogeneously enhancing mass (arrows) in the mid belly of the left psoas muscle. 

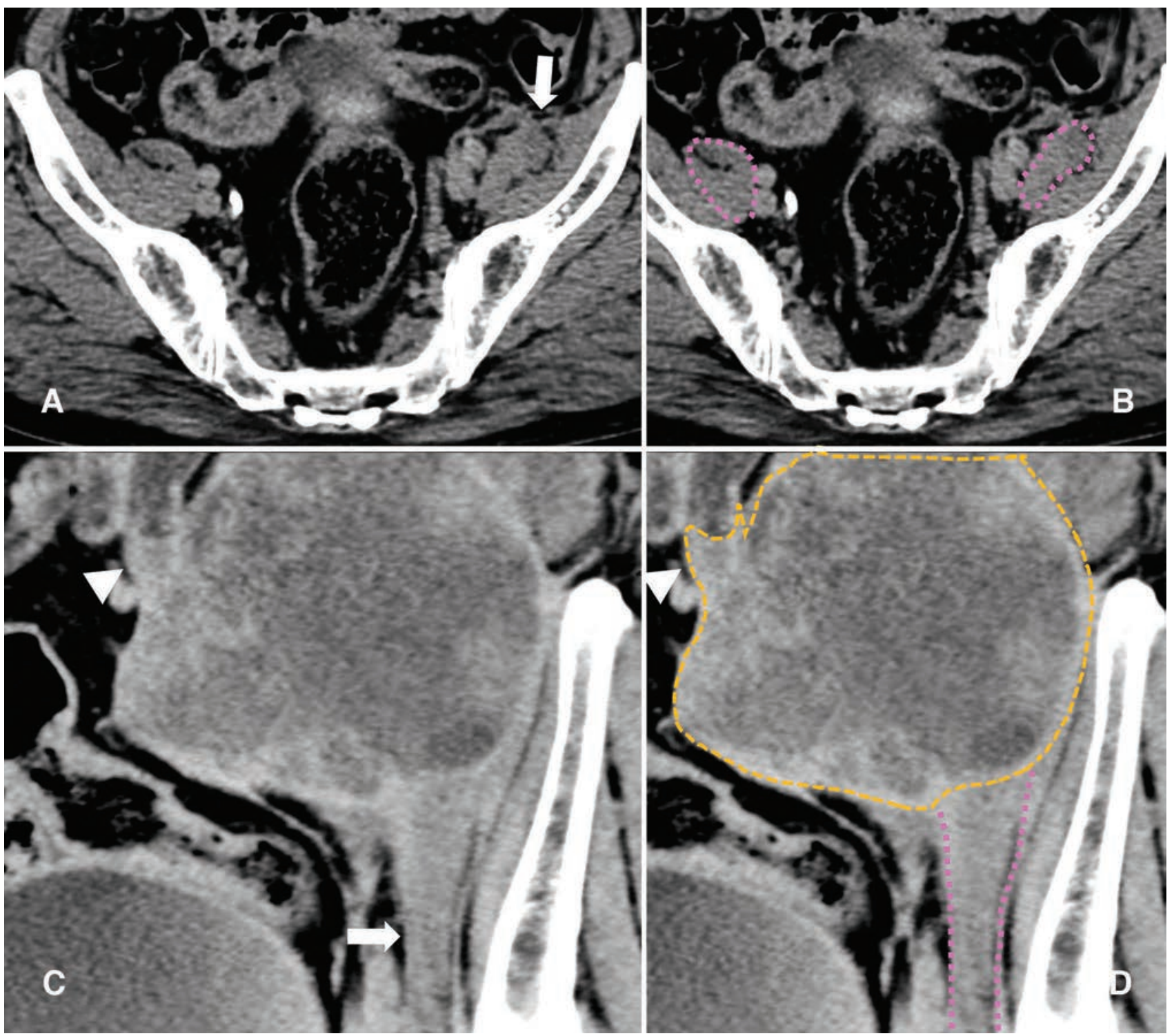

Fig. 3 (A, B) Axial CT sections reveal no involvement of the distal psoas (arrow in A, both psoas outlined in pink in B). (C, D) Oblique coronal sections in delayed phase show the lower limit of the mass outlined in orange and distal-free psoas outlined in pink. The arrowhead points to the growth into the ureter.

any thinning of the renal parenchyma. The kidney revealed a reduced parenchymal enhancement in the arterial and venous phases and did not show any contrast excretion in the 10 minutes delayed scan. The contralateral kidney, ureter, and urinary bladder were normal.

\section{Characterization of the Mass}

The mass appeared predominantly necrotic with irregular solid areas peripherally enhancing moderately (60-70 HU [Hounsfield units]) in the venous and delayed phases. No dilated vascular channels could be seen around the mass suggestive of large supplying arteries or draining veins. Its surfaces, though mildly lobulated, were fairly smooth, and it appeared like a ball suspended in mid psoas tethered to the ureter. The extension into the ureteric lumen revealed significant enhancement in the venous phase (80-90 HU). The presence of solid areas peripherally within the mas and the enhancing intraureteric component firmly established the diagnosis of a tumor and not an abscess despite the large central necrotic component. The presence of necrosis pointed to the fact that it was malignant.

In addition to the main mass, there were two satellite nodules showing central necrosis and peripheral rim-like enhancement in the psoas located cranial to the mass measuring about 2 to $2.5 \mathrm{~cm}$. There were also seven to eight heterogeneously enhancing, rounded to ovoid enlarged nodes located longitudinally along the medial aspect of the left ureter in the left para-aortic region at the level of the ureteric involvement by the mass. The largest of these measured $1.8 \times 0.8 \mathrm{~cm}$. A large similar-appearing node was also seen in the left para-aortic region at the level of the left renal hilum measuring $3.3 \times 2.4 \mathrm{~cm}$ (-Figs. 4A, 6A). Because satellite nodules and nodal secondaries are rare with sarcomas and common with carcinomas, a final diagnosis of an exophytic 


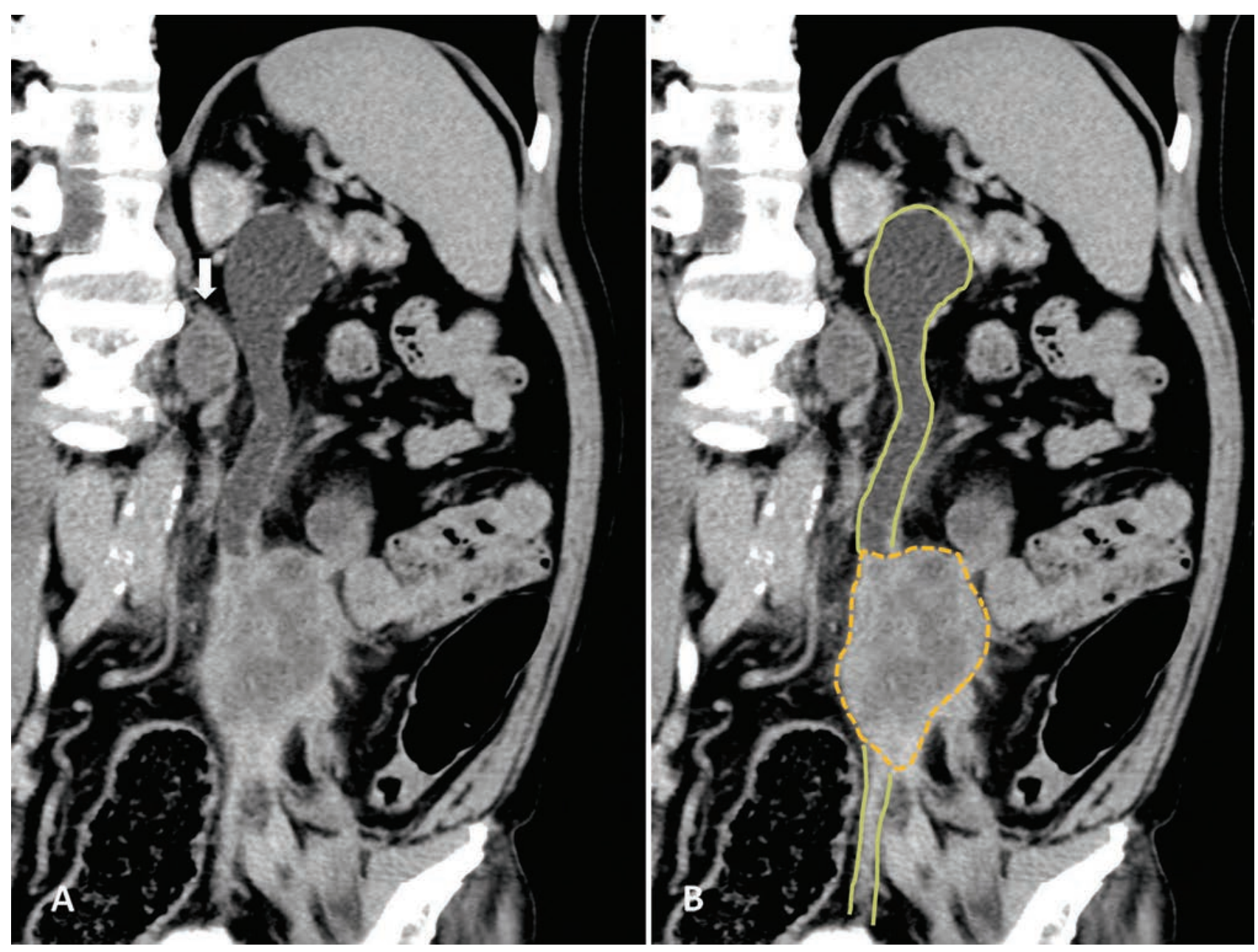

Fig. 4 (A, B) Oblique coronal reconstructions in the delayed phase show the mass (outlined in orange) infiltrating the ureter (outlined in yellow). The arrow in panel A points to the large heterogeneous metastatic left para-aortic node at the left renal hilar level.

transitional cell carcinoma (TCC) of the mid left ureter infiltrating the underlying psoas muscle was made. The mass appeared closely applied to the left common iliac artery. However, no infiltration of the artery was seen. A superficial adherence to the artery could not be ruled out. The left common iliac vein was compressed but uninvolved. Overall the mass appeared to be resectable.

\section{Management Plan}

A fine-needle aspiration biopsy guided by US was performed. It showed linear cores of tumor with large areas of infarction. The viable tumor cells were large, round to polygonal with vesicular nuclei and prominent nucleoli. Tumor giant cells were seen. Many mitotic figures were present. The stroma was hyalinized. In some foci, the cells showed spindling. The features were conclusive of a high-grade sarcoma, namely undifferentiated leiomyosarcoma (LMS) or a pleomorphic sarcoma. A management plan of total excision of the tumor with the left kidney and clearance of lymph nodes was made.

\section{Intraoperative Findings}

The entire colon was mobilized on the left side. The left renal vascular pedicle was ligated. The left kidney was mobilized en bloc with the tumor. The left iliac vessels were dissected away from the tumor, and no adherence was found ( $\sim$ Fig. 7A-C). The tumor was mobilized posteriorly from the psoas and iliacus musculature. The iliacus muscle was found involved. The femoral nerve entrapped within the mass was divided en bloc in the resection. Wide resection of the tumor was achieved and delivered en bloc with the kidney and ureter (-Fig. 8). Postoperatively, the patient had left thigh flexion weakness with a muscle power of $2 / 5$. Physiotherapy was initiated, and the muscle power was $4 / 5$ at the time of discharge.

\section{Pathological Findings}

- Gross pathology: A soft tissue mass was seen attached to the left ureter encasing it ( $\boldsymbol{- \text { Fig. }} \mathbf{9}$ ). On the posterior surface, the muscle was seen attached to the tumor. On the cut surface, the tumor appeared grayish white and friable and seen to involve the ureteric wall circumferentially.

- Histopathology: The sections of the ureter show the urothelium surrounded by the tumor replacing the muscle

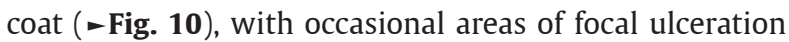
(-Fig. 11). However, no involvement of the urothelium could be identified. The tumor is composed of cellular 

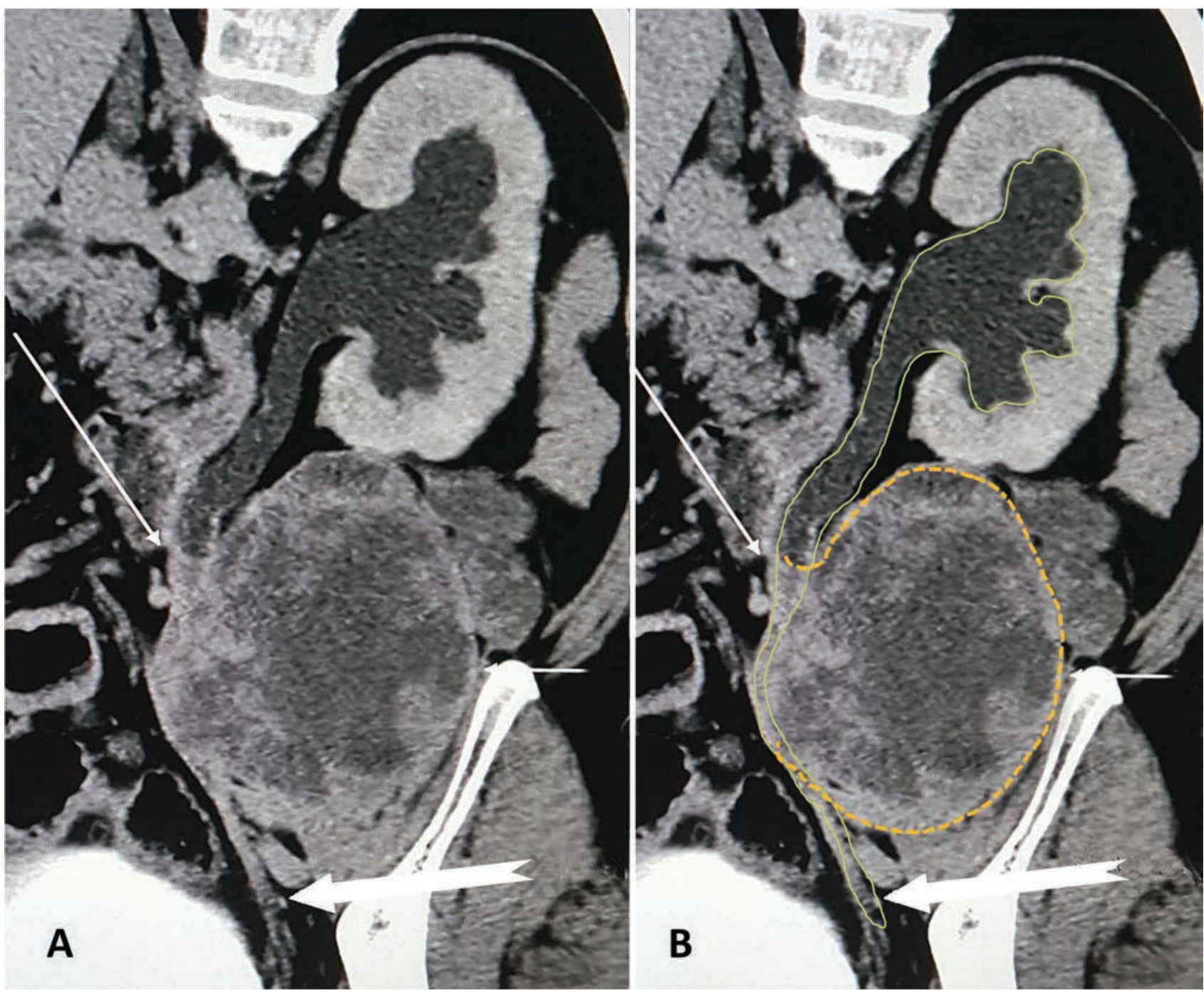

Fig. 5 (A, B) Oblique sagittal CT reconstructions in the delayed phase show the mass (orange outline, short thin arrow) involving along segment of the mid ureter (yellow outline) along its posterior aspect and entrapping it. Proximal hydroureteronephrosis is seen. Distal ureter is marked by the notched arrow. The long thin arrow marks the growth along the ureter cranially for a short length.

areas with large foci of necrosis ( - Fig. 12). The cellular areas comprise fascicles of spindle cells with marked nuclear pleomorphism and anaplasia (-Fig. 13). Focal angiovascular invasion is noted. Many mitotic figures are seen. In some foci, the tumor shows epithelioid appearance and is arranged in sheets ( $\mathbf{- F i g}$. 14). Four of the six lymph nodes show tumor. A conclusion of high-grade spindled and epithelioid malignant neoplasm from the ureter was made with differentials of an LMS and sarcomatoid carcinoma.

- Immunohistochemistry: The tumor was positive for vimentin and desmin that are markers for mesenchyme and sarcoma, respectively, with focal positivity for pan cytokeratin (AE1 + A3), and cytokeratin (B1) that are markers for epithelial neoplasms. It also showed focal positivity for smooth muscle actin (SMA), mild focal positivity for h-Caldesmon that is a marker for smooth muscle neoplasms, and mild positivity of muscle-specific antigen and GATA3 that is a marker for urothelial neoplasms. It was negative for epithelial membrane antigen, P63, cytokeratin 7 , cytokeratin 20 , high-molecular-weight cytokeratin, and S100.

A conclusion of a poorly differentiated high-grade malignant neoplasm, with immunohistochemistry showing features suggestive of leiomyosarcomatous differentiation, was made (-Figs. 15, 16). Because no involvement of the urothelium could be identified, the areas of ulceration in the urothelium were attributed to ischemic necrosis and a urothelial malignancy was ruled out with a final diagnosis of a primary LMS of the ureter.

\section{Discussion}

Retroperitoneal Anatomy, Fascia, and Communications Retroperitoneal fasciae were found by anatomists, such as Cooper, Treitz, and Toldt, in the 19th century. Until then, it had been believed that the retroperitoneum is a noncompartmentalized area containing fatty tissues and acting as a cushion. The discovery of the posterior renal fascia by Zuckerkandl and of the anterior renal fascia by Gerota changed that concept. 

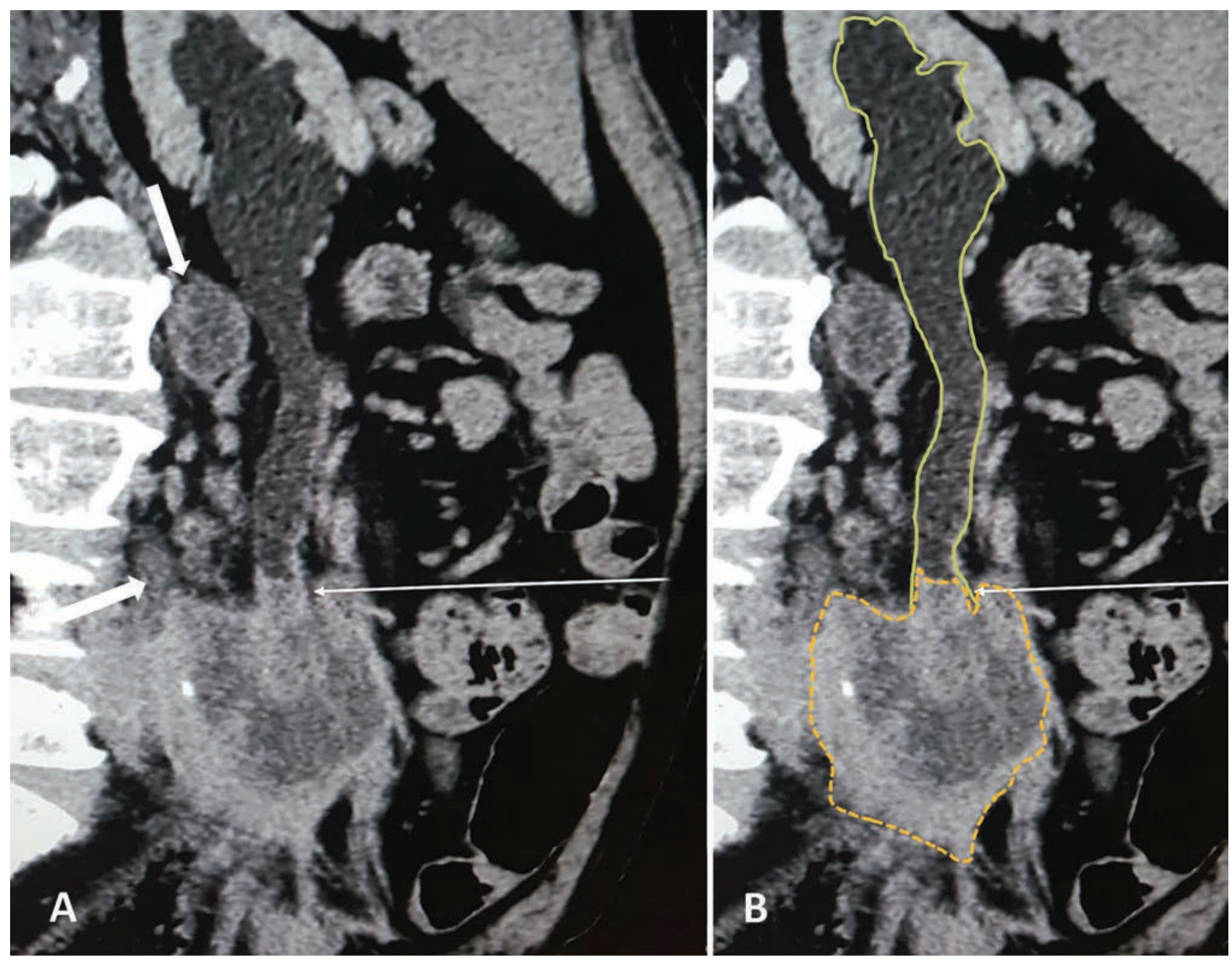

Fig. 6 (A, B) Oblique coronal reconstruction in delayed venous phase shows the mass growing cranially along the ureteric wall. Arrows in panel $A$ point to enlarged heterogeneous nodes in the left para-aortic region medial to the ureter.

Meyers et al established the tricompartmental theory of the retroperitoneum. ${ }^{1}$ The retroperitoneum is now understood to be a space bounded anteriorly by the parietal peritoneum (PP) and posteriorly by the transversalis fascia (TF) that underlies the transverse abdominis muscle. It is divided into five compartments ( - Fig. 17). A central compartment is seen extending from D12 to L4-L5 and containing the aorta, inferior vena cava, renal and lumbar vessels, sympathetic trunk, and lymphatics. One lateral compartment is seen on either side of this and two posterior compartments on either side, which house the iliopsoas muscles.

The lateral compartments are further subdivided into the anterior pararenal space (APRS), posterior pararenal space (PPRS), and perirenal space (PRS). The APRS is bounded anteriorly by the PP and posteriorly by the anterior renal or the Gerota's fascia (GF). It contains the pancreas, ascending and descending colon, and duodenum. The PRS is bounded by the GF anteriorly and the posterior renal or Zuckerkandl's fascia (ZF) posteriorly. It contains the kidneys, ureters, and adrenal glands. The PPRS is bounded anteriorly by the ZF continuing as the lateroconal fascia (LCF) laterally and the TF posteriorly. It contains only fat.
The two posterior compartments, also called the psoas compartments, contain the psoas major muscle (PM), which joins with the iliacus and, occasionally, the psoas minor muscles. The iliopsoas compartment, though located posterior to the TF, is considered a part of the retroperitoneum as it is often involved by retroperitoneal diseases. The PM arises from the anterior surfaces of the lower borders of the transverse processes and vertebral bodies of T12-L5 and inserts into the lesser trochanter. The psoas minor muscle lies in front of the PM, arising from the sides of the T12 and L1 vertebral bodies and inserts into the pectineal line and iliopectineal eminence. Its lateral border merges into the iliac fascia. The iliacus muscle arises from the upper two-thirds of the iliac fossa and inserts into the lateral aspect of the PM tendon and the anteroinferior aspect of the lesser trochanter., ${ }^{2,3}$

Though it was initially thought that the retroperitoneal compartments are tightly bound, it was later discovered that these spaces in fact communicate with each other with ability of disease to spread from one compartment to the other. There is free communication between the two APRS behind the duodenum and pancreas. The APRS also communicates potentially with the spaces located along the transverse mesocolon, 

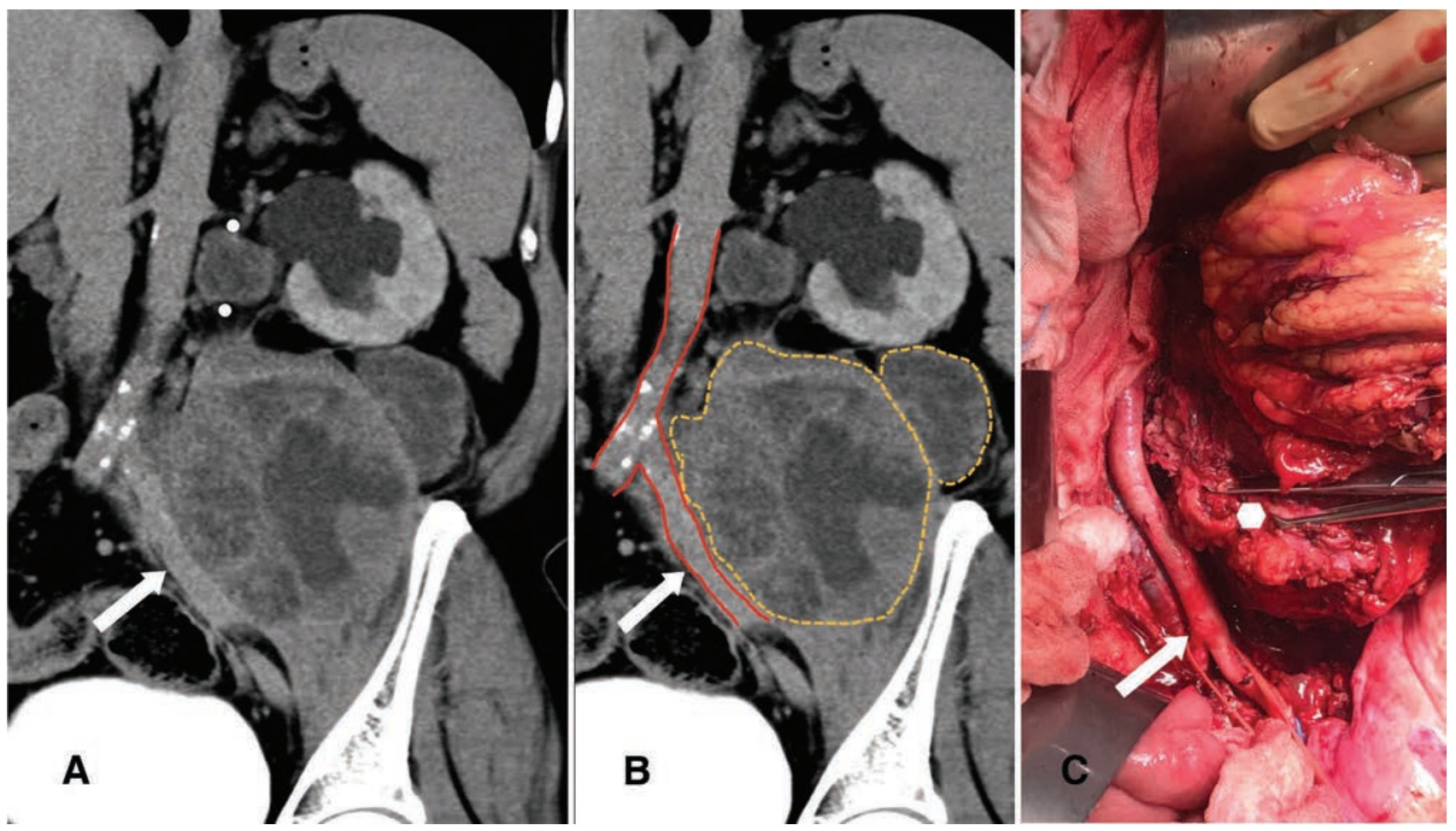

Fig. 7 (A, B) Oblique coronal CT reconstruction in the delayed phase shows the relationship of the mass (orange outline) to the aorta and left common iliac artery (arrow and red outline). (C) Corresponding intraoperative photograph. Arrow marks the bifurcation of the left common iliac artery. The mass (white solid hexagon) has been cleanly dissected away from the artery. The left renal hilar metastatic node is marked between white dots in panel A.

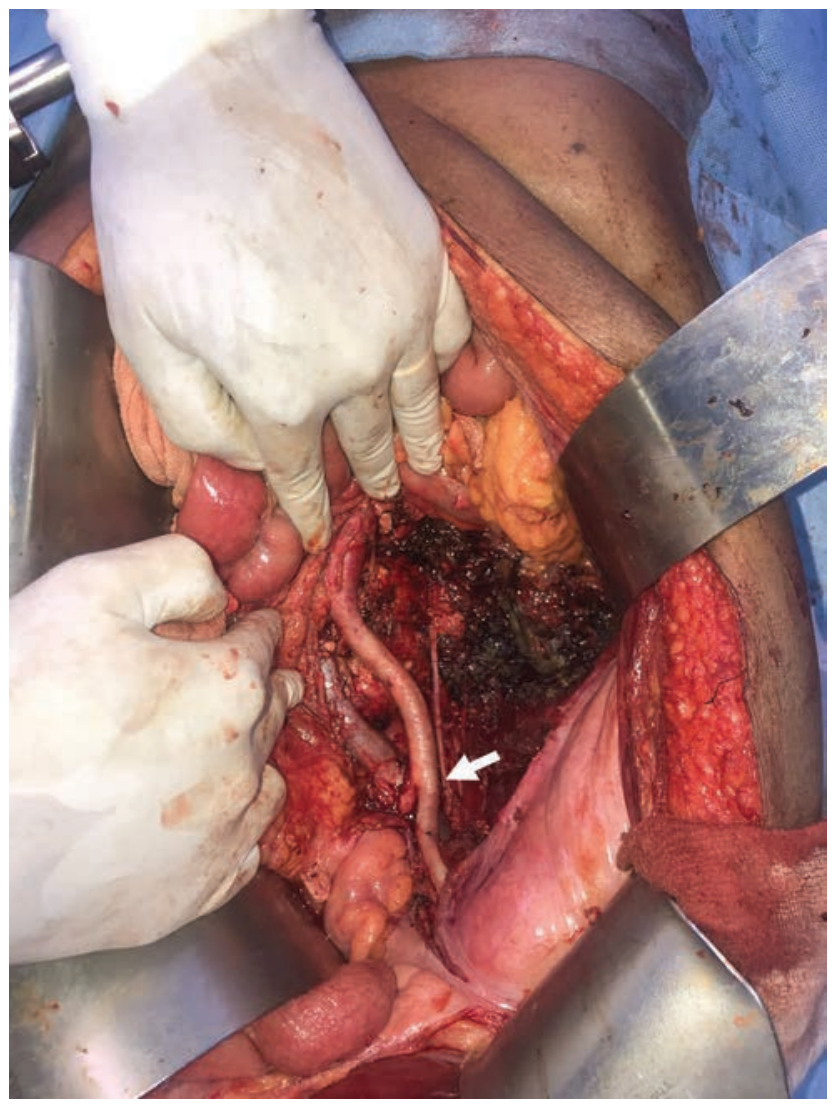

Fig. 8 Intraoperative photograph shows bed after the mass has been resected en bloc. Arrow points to bifurcation of the left iliac artery.

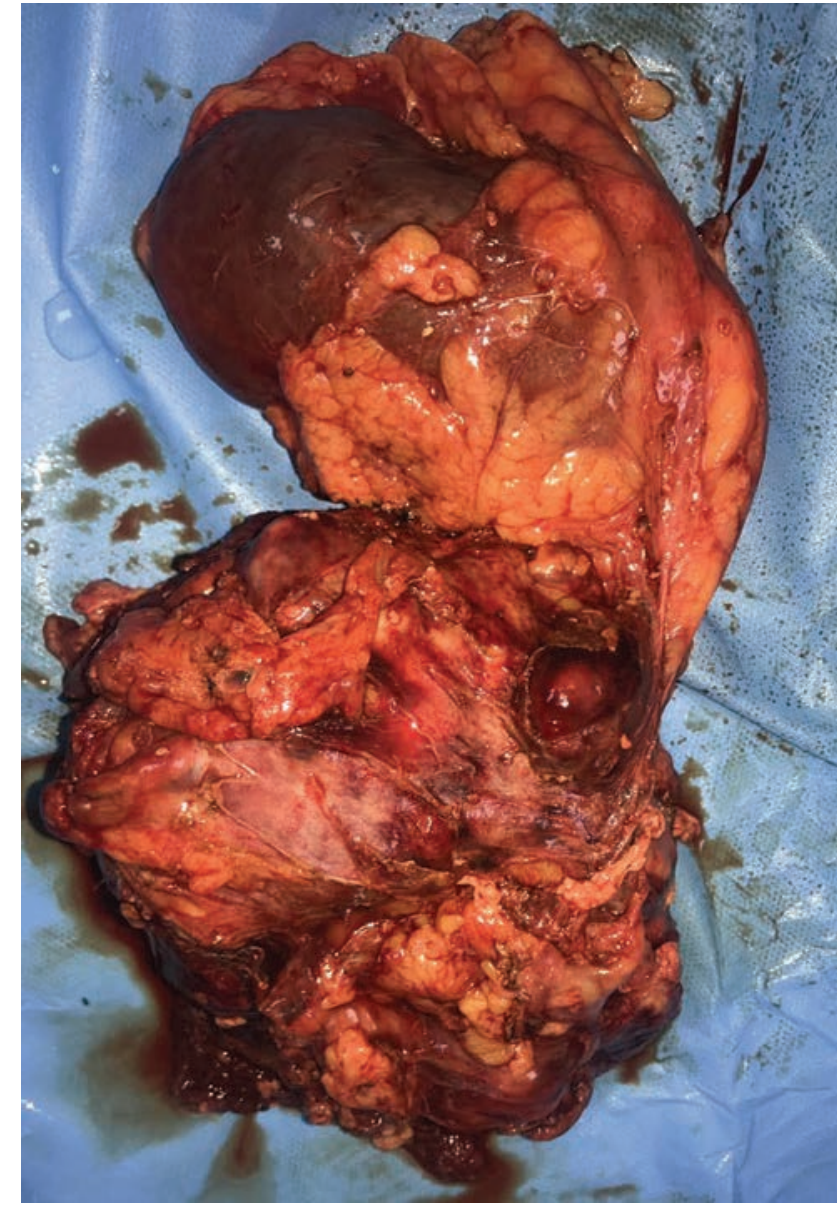

Fig. 9 Gross pathology shows specimen with the kidney at the upper part and the mass at the lower part. 


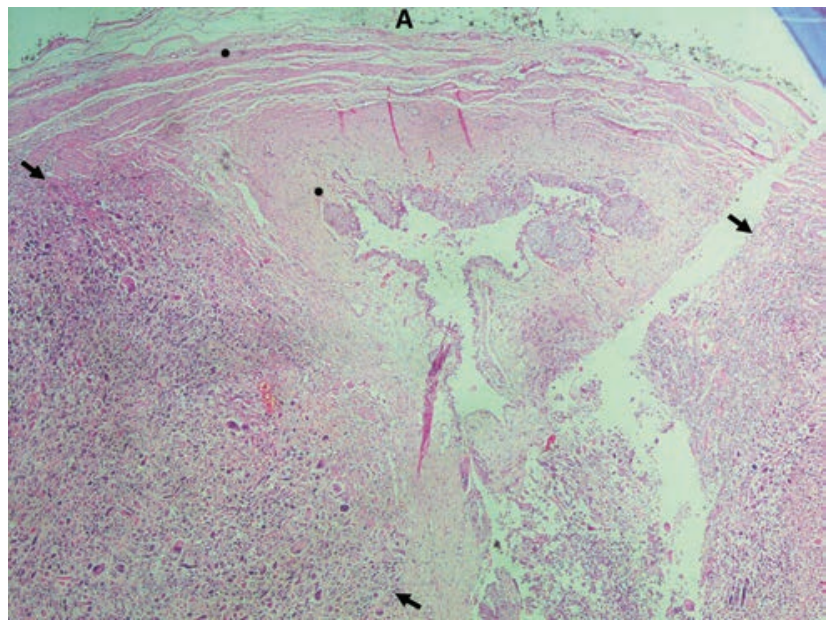

Fig. 10 Low-power $4 \times$ hematoxylin-eosin histopathology section reveals a tumor (arrows) replacing the muscular layer (within black dots) and invading from the posterior wall. A, anterior.

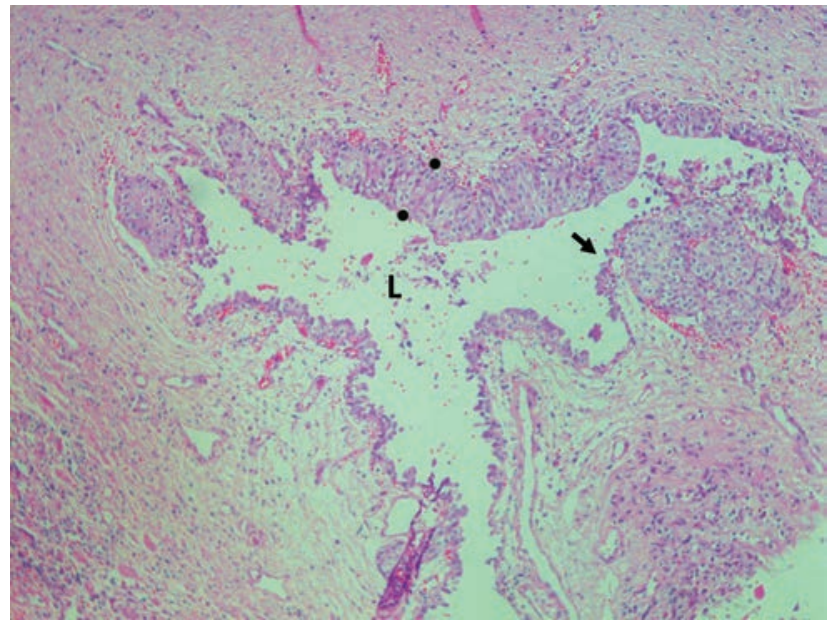

Fig. 11 Hematoxylin-eosin 10x histopathology section reveals a focus of ulceration of the mucosa (arrow). The normal urothelium is marked between the black dots along the anterior wall of the ureter. $\mathrm{L}$, lumen.

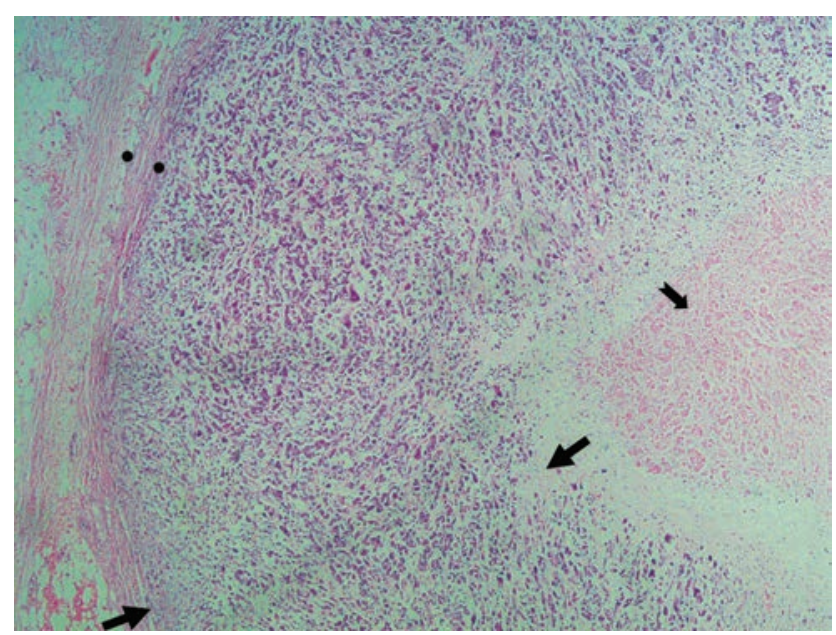

Fig. 12 Hematoxylin-eosin 40x histopathology section reveals the tumor growing in the muscular layer of the ureter composed of cellular areas (within block arrows) with large foci of necrosis (notched arrow). Remnant normal circular muscle layer is seen outer to the tumor (within black dots).

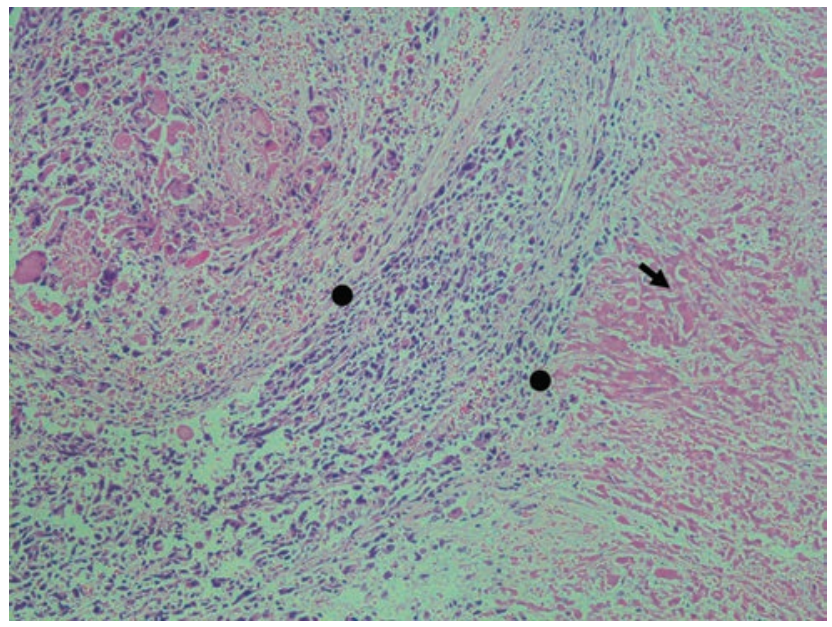

Fig. 13 Hematoxylin-eosin 40x histopathology section reveals cellular areas of tumor (within dots) comprising fascicles of spindle cells with marked nuclear pleomorphism and anaplasia. The nonviable necrotic tumor is marked by an arrow.

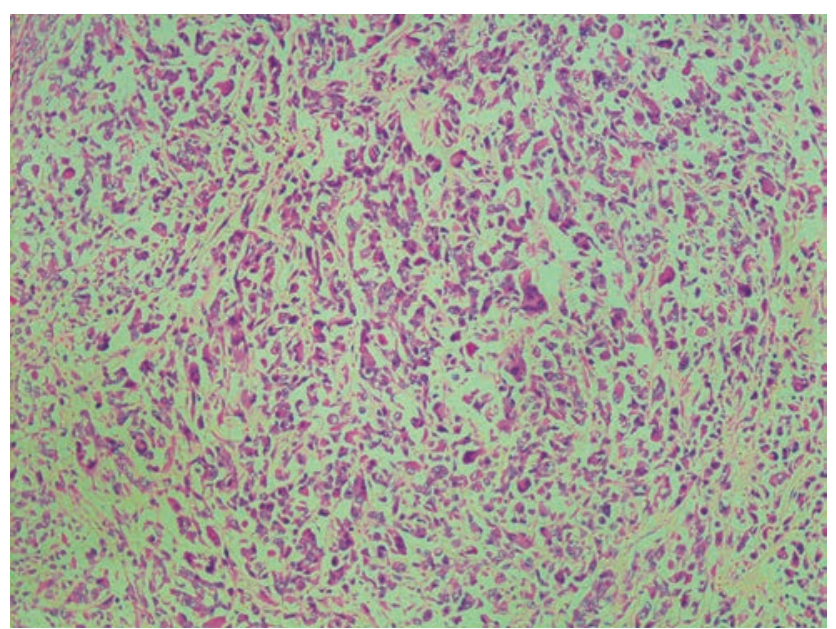

Fig. 14 Hematoxylin-eosin high-power 400× histopathology section reveals spindle and epithelioid cells with nuclear pleomorphism.

small bowel mesentery, and sigmoid mesocolon. This provides a route for fluid collections to extend from the APRS between the leaves of these mesentery and track around the transverse or sigmoid colon or even small bowel without entering the peritoneal cavity. The APRS also communicates caudally with the pelvis as it runs along the anterior surface of the ureters.

The PRS has the shape of an inverted cone with the apex directed at the pelvis and the base at the diaphragm. Superiorly the PRS touches the diaphragm. On the right, the bare area of the liver uncovered by the peritoneum is in continuity with the PRS. There is a potential midline communication between the two PRS called the Kneeland channel ( - Fig. 17). Inferiorly the PRS is deficient at the apex of the cone. The ureter lies in the perirenal space and runs toward the pelvis through this deficiency passing under the PP at one point just before it crosses anterior to the iliac vessels ( - Fig. 18). On the left, the ureter runs between the primary root of the sigmoid mesocolon and iliac vessels. In the pelvic cavity, the ureter with its surrounding renal fasciae passes between the mesorectal fascia medially and the fasciae surrounding the neurovascular 

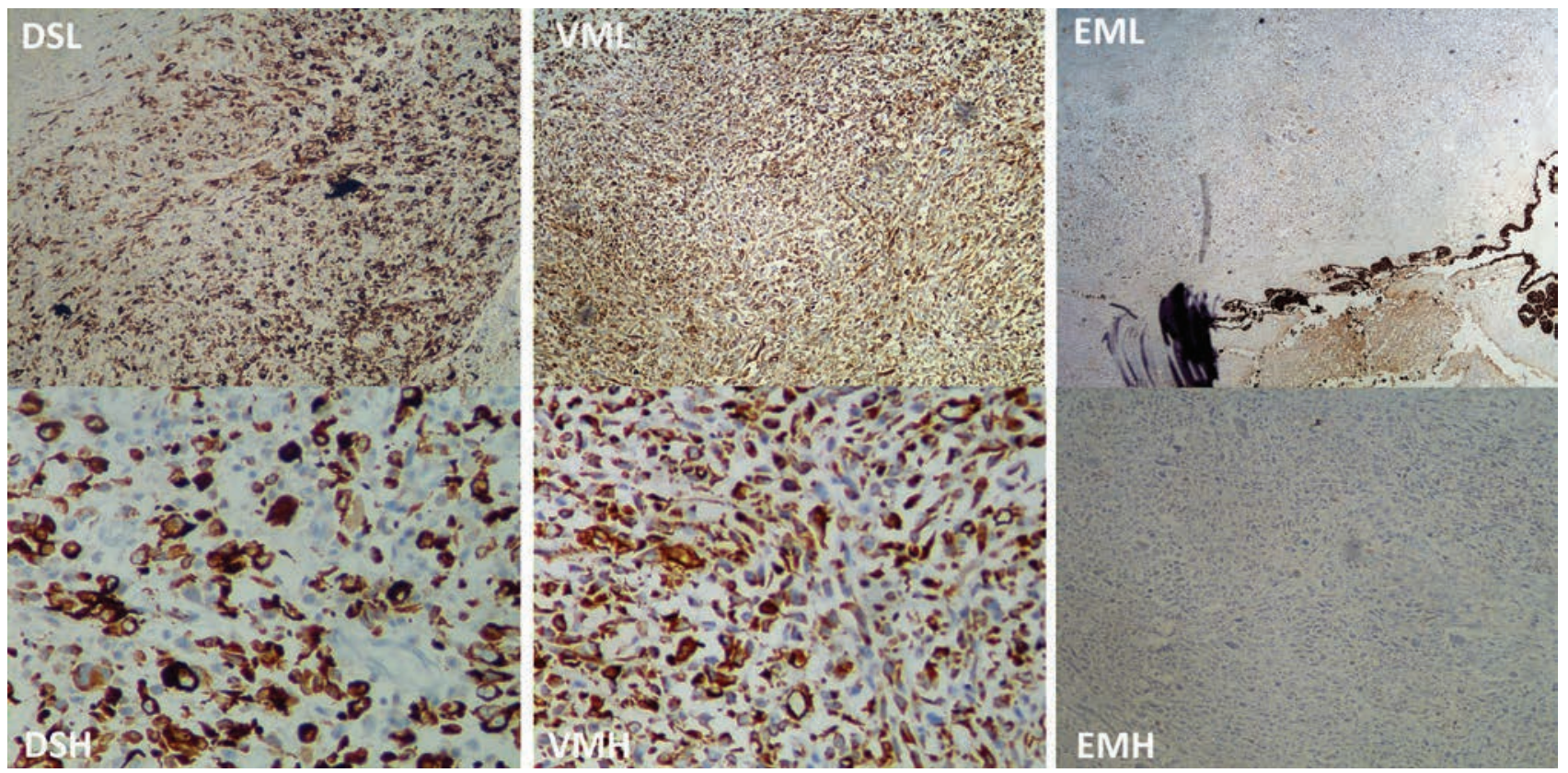

Fig. 15 Immunohistochemistry. DSH, desmin high power; DSL, desmin positivity low power; EMH, epithelial membrane antigen high power; EML, epithelial membrane antigen negativity low power; VMH, vimentin high power; VML, vimentin positivity low power.

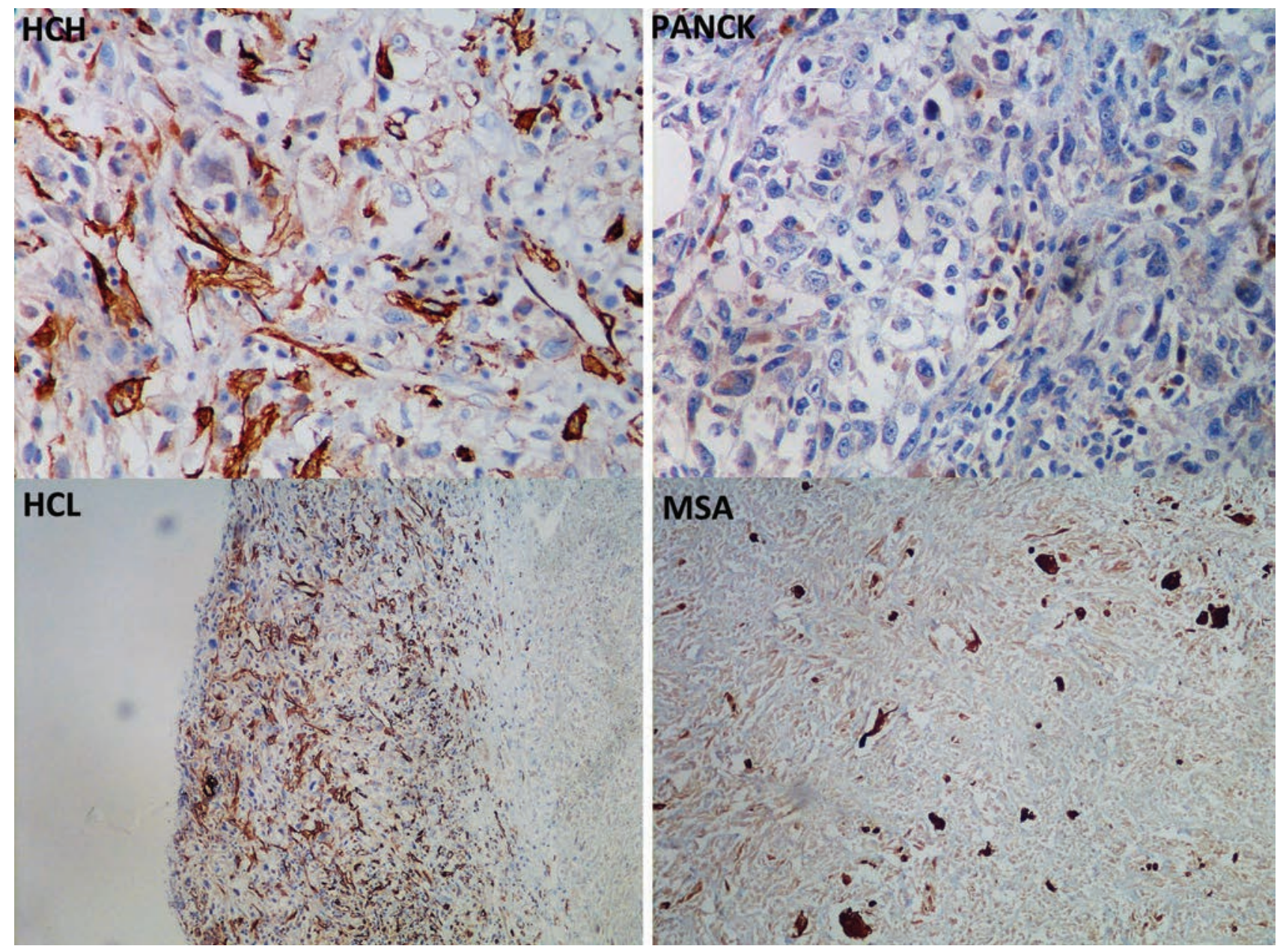

Fig. 16 Immunohistochemistry. $\mathrm{HCH}$, h-Caldesmon high power, $\mathrm{HCL}$, h-Caldesmon mild focal positivity low power; MSA, muscle-specific antigen mild positivity; PANCK, pan cytokeratin (AE1 + A3) focal positivity. 


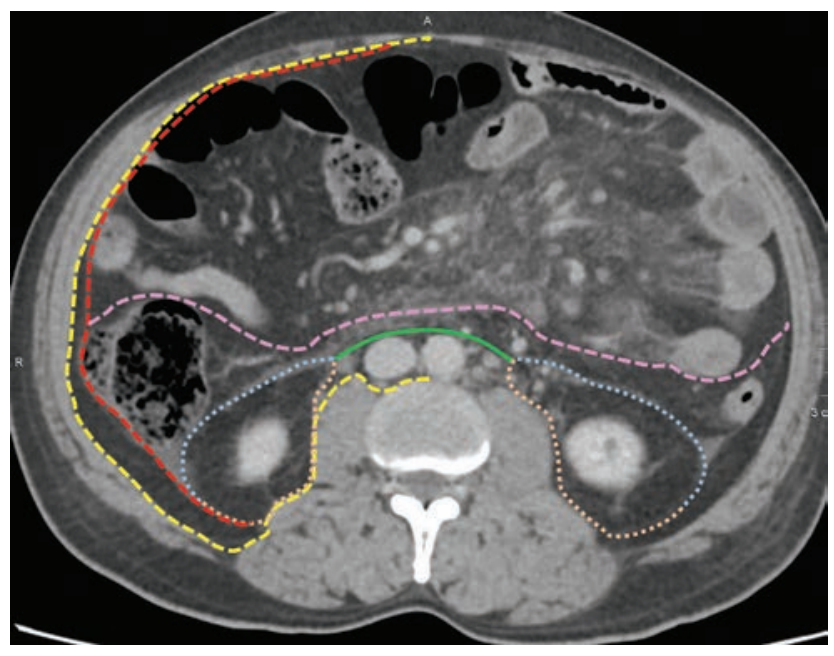

Fig. 17 Axial scan through the abdomen of another patient with various retroperitoneal compartments and their boundaries with various fascia in the following colors: GF, blue; Kneeland channel, green; LCF, red; PP, pink; TF, yellow; ZF, orange.

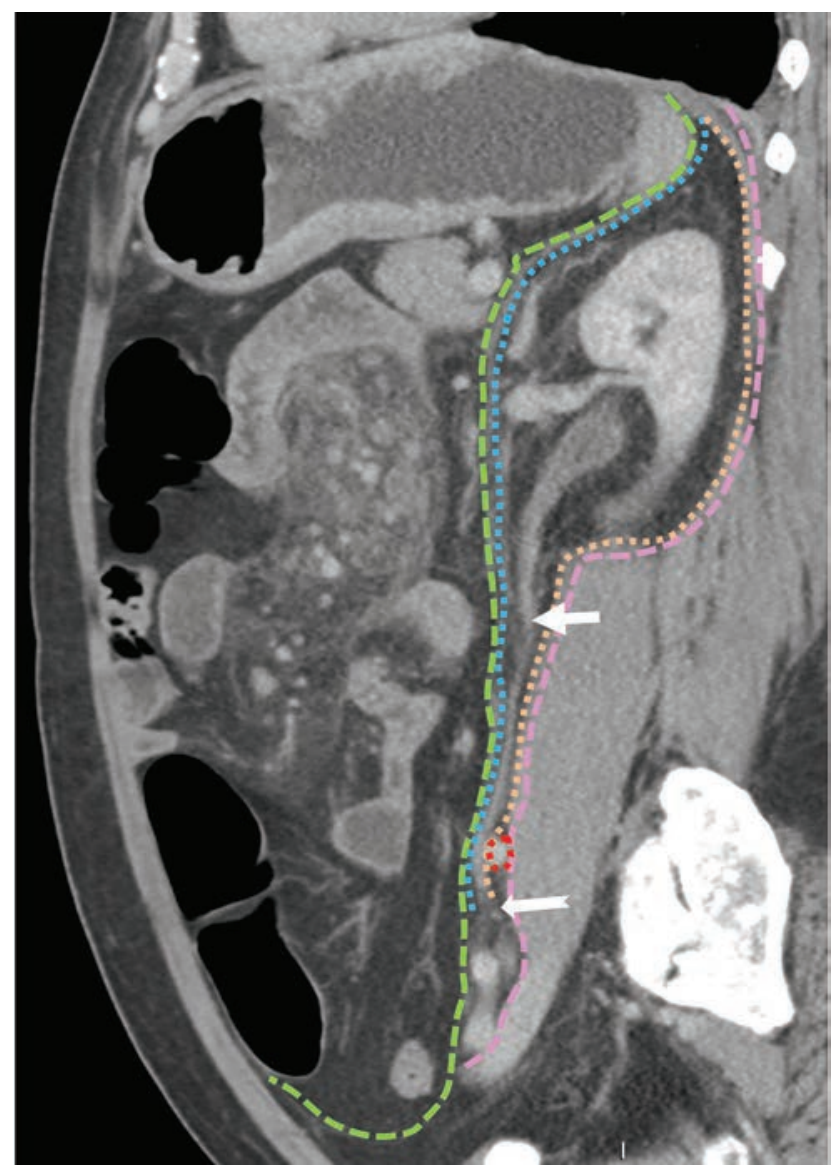

Fig. 18 Sagittal section through the abdomen of another patient shows the course of the ureter (arrow) through the perirenal space and as it exits via the inferior defect in the space to the pelvis (notched arrow) crossing the iliac vessels (red circle). The PRS relates to the dome of the diaphragm cranially. GF, blue; PP, green; TF, pink; ZF, orange.

bundles along the lateral pelvic walls and then opens into the

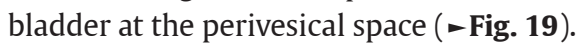

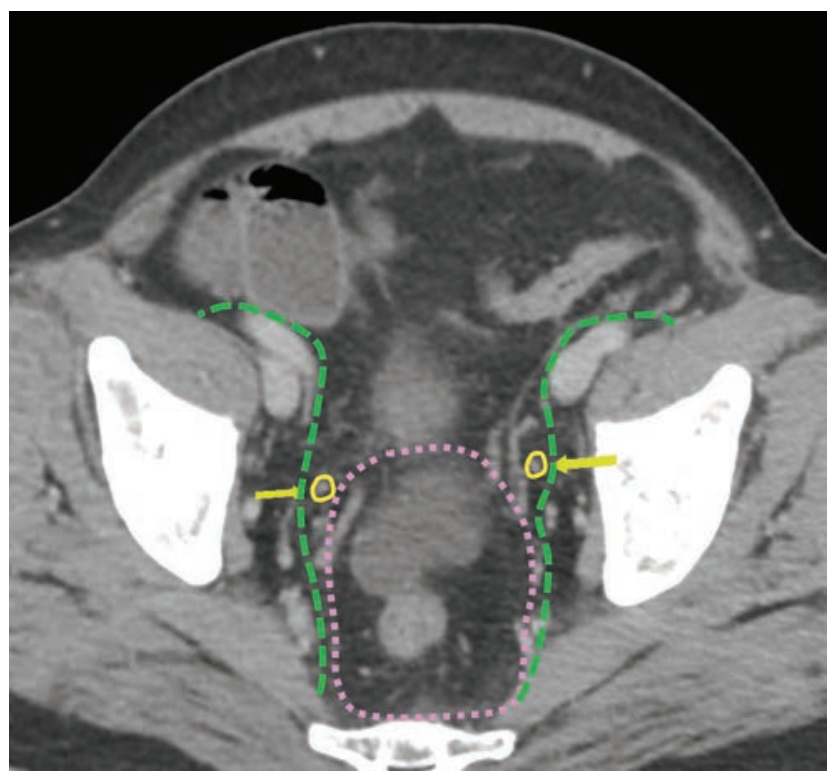

Fig. 19 Axial section through the pelvis of another patient shows the ureters (yellow circles and arrows) coursing in the perivesical space toward the bladder between the mesorectal fascia (pink) and the fascia covering the lateral pelvic vessels and nerves (green).

The PPRS extends along the posterior and lateral abdominal wall under the transversus abdominis muscle, and in the pelvis, it extends around anteriorly lying in the properitoneal space up to the midline. ${ }^{2}$ Along the posterior boundary of the PPRS, the TF is continuous with the endothoracic fascia cranially and with the fascia lata of the thigh caudally enabling the spread of disease from thoracic cavity and vice versa. ${ }^{3}$

\section{Localization of Retroperitoneal Masses}

Large abdominal masses may distort the anatomy, and in such cases, distinction between peritoneal and retroperitoneal masses can be challenging. However, displacement of retroperitoneal organs is a useful indicator that a tumor is retroperitoneal in origin. ${ }^{4}$ For example, displacement of the ascending or descending colon anteriorly or the kidney and ureter medially or anteriorly, the pancreatic tail anteriorly places the mass squarely in the retroperitoneal compartment. Further intracompartmental localization is possible by observing displacement of the organs with relation to one and another. For example, if a mass displaces the second part of the duodenum medially and to the left while displacing the right kidney posteriorly, it arises from the right APRS. In our case, the tumor was predominantly in the psoas space and a primary psoas neoplasm would be the logical conclusion. However, it was tethered to the ureter and entrapping it. The diagnostic dilemma therefore was whether the mass arose exophytically from the ureter and involved the psoas muscle or vice versa. Tumor involvement of the iliopsoas muscle is rarely primary and most often secondary to direct extension of tumor from an adjacent organ or invasion from adjacent lymph nodes and local tumor recurrence. ${ }^{3}$ Also, primary sarcomas of the iliopsoas compartment are extremely rare. ${ }^{5}$ This pointed to a likely primary from the ureter rather than PM. 
It is known that cancer grows locally in a centrifugal manner and certain tissues such as major fascia act as natural barriers to spread. ${ }^{6}$ One may argue that a mass arising from the PM would be prevented by the combined TF and ZF, which cover its belly anteriorly, from any anterior spread to involve the ureter as it did in our case. It would then ideally be expected to follow a path of least resistance and extend craniocaudally diffusely within the psoas space following the contour of the space bulging it from within outward ( - Fig. 20). In our case, the mass remained focally within the mid belly of the psoas at its site of attachment to the ureter, which led us to believe that it arose from the ureter rather than the psoas. However, fascial disruption has been reported with equal frequency in malignant and benign lesions of the psoas compartment and cannot be considered a good predictor of the compartment of origin of a retroperitoneal mass. ${ }^{3}$

Some radiologic signs helpful in determining tumor origin include the "beak sign," the "phantom (invisible) organ sign" and the "embedded organ sign." Beak sign is positive when a mass deforms the edge of an adjacent organ into a "beak" shape, forming an acute angle between itself and the organ, and it is likely that the mass arises from that organ. On the other hand, when the angle between the tumor and organ is obtuse with rounded edges, it is likely that the tumor compresses the organ but does not arise from it. When a large mass arises from a small organ, the organ sometimes becomes undetectable. This is known as the phantom organ sign. However, in cases of huge retroperitoneal sarcomas that involve other small organs such as the adrenal glands, the sign may be false positive and indicate the adrenal gland as the organ of origin. When a tumor compresses an adjacent organ, it forms a crescent-shaped interface with it and an adjacent fat plane may be visible showing that the tumor does not arise from it. However, when a part of the organ is embedded within the tumor, it is likely that the tumor arises from it. In our case, the ureter was embedded in the tumor, which led us to accurately identify the ureter as the structure of origin (-Fig. 21).

Metastatic draining nodes are also a good pointer to the structure of origin. In this case, metastatic nodes were seen at paraaortic and left renal hilar regions that drain the proximal and mid ureter (Figs. 4A, 6A).

\section{Characterization of Retroperitoneal Masses by Components}

A list of commonly found soft tissue tumors of the retroperitoneum is given in - Table 1. Retroperitoneal sarcomas have an incidence of 0.5 to 1 per 100,000 cases $^{7}$ and account for one-third of the retroperitoneal tumors. ${ }^{4}$ Primary LMS of the ureter is extremely rare with 23 cases reported in the literature. Ours is the 24th case. These have a female preponderance and a poor prognosis. Most cases present with flank pain, hydronephrosis, and, less commonly, with hematuria. Several have been reported to be large $(9-12 \mathrm{~cm}){ }^{8}{ }^{8-15}$

Contrast-enhanced multidetector computed tomography (MDCT) is the most useful and widely available primary imaging investigation for characterization of retroperitoneal masses. Magnetic resonance imaging (MRI) is reserved for
Table 1 Soft tissue tumors of the retroperitoneum

\begin{tabular}{|c|c|c|}
\hline $\begin{array}{l}\text { Tissue of } \\
\text { origin }\end{array}$ & Benign & Malignant \\
\hline $\begin{array}{l}\text { Adipose } \\
\text { tissue }\end{array}$ & Lipoma & Liposarcoma \\
\hline $\begin{array}{l}\text { Smooth } \\
\text { muscle }\end{array}$ & Leiomyoma & Leiomyosarcoma \\
\hline $\begin{array}{l}\text { Connective } \\
\text { tissue }\end{array}$ & Fibroma & $\begin{array}{l}\text { Malignant fibrous histio- } \\
\text { cytoma, fibrosarcoma, } \\
\text { chondrosarcoma, synovi- } \\
\text { al sarcoma }\end{array}$ \\
\hline $\begin{array}{l}\text { Striated } \\
\text { muscle }\end{array}$ & Rhabdomyoma & Rhabdomyosarcoma \\
\hline $\begin{array}{l}\text { Blood } \\
\text { vessels }\end{array}$ & $\begin{array}{l}\text { Hemangioma, } \\
\text { hemangioperi- } \\
\text { cytoma }\end{array}$ & Angiosarcoma \\
\hline $\begin{array}{l}\text { Lymphatic } \\
\text { tissue }\end{array}$ & Lymphangioma & \\
\hline $\begin{array}{l}\text { Perivascular } \\
\text { epithelioid } \\
\text { cells }\end{array}$ & $\begin{array}{l}\text { Angiomyoli- } \\
\text { poma }\end{array}$ & Sarcoma \\
\hline $\begin{array}{l}\text { Interstitial } \\
\text { cells of Cajal }\end{array}$ & $\begin{array}{l}\text { Gastrointestinal } \\
\text { stromal tumors } \\
\text { (GIST) benign }\end{array}$ & Malignant \\
\hline $\begin{array}{l}\text { Primitive } \\
\text { mesenchyme }\end{array}$ & Myxoma & Myxosarcoma \\
\hline $\begin{array}{l}\text { Notochord } \\
\text { remnant }\end{array}$ & Chordoma & \\
\hline $\begin{array}{l}\text { Miscella- } \\
\text { neous }\end{array}$ & $\begin{array}{l}\text { Myelolipoma, } \\
\text { fibromatosis }\end{array}$ & \\
\hline $\begin{array}{l}\text { Nerve } \\
\text { sheath }\end{array}$ & $\begin{array}{l}\text { Schwannoma, } \\
\text { neurofibroma }\end{array}$ & Sarcoma \\
\hline $\begin{array}{l}\text { Sympathetic } \\
\text { chain }\end{array}$ & $\begin{array}{l}\text { Ganglioneu- } \\
\text { roma }\end{array}$ & Neuroblastoma \\
\hline $\begin{array}{l}\text { Chromaffin } \\
\text { cells }\end{array}$ & $\begin{array}{l}\text { Paraganglioma, } \\
\text { pheochromocy- } \\
\text { toma }\end{array}$ & Malignant varieties \\
\hline $\begin{array}{l}\text { Germ cell } \\
\text { and sex cord } \\
\text { stromal } \\
\text { tissue }\end{array}$ & $\begin{array}{l}\text { Mature and } \\
\text { immature tera- } \\
\text { toma, granulo- } \\
\text { sa cell tumor, } \\
\text { thecoma, } \\
\text { Sertoli-Leydig } \\
\text { cell tumor }\end{array}$ & $\begin{array}{l}\text { Malignant teratoma, } \\
\text { seminoma, yolk sac } \\
\text { tumor, choriocarcinoma, } \\
\text { mixed germ cell tumor }\end{array}$ \\
\hline $\begin{array}{l}\text { Hematologic } \\
\text { tissue }\end{array}$ & & $\begin{array}{l}\text { Lymphoma, } \\
\text { plasmacytoma }\end{array}$ \\
\hline
\end{tabular}

patients with allergy to iodinated contrast agents or problem solving where, for example, muscle, bone or spinal foraminal involvement is equivocal on CT. MRI may also be useful for delineating disease in the pelvis. FDG positron emission tomography-computed tomography (PET-CT) has no routine role. It is used when pulmonary abnormalities are detected on $\mathrm{CT}$, which may be suspicious but not diagnostic for metastasis or to evaluate possible multifocal intra-abdominal disease. ${ }^{4}$

A retroperitoneal mass can be characterized by its components on MDCT and MRI. Those that contain fat can be recognized by their negative HU value on MDCT and high intensity on T1W images with loss of signal intensity 


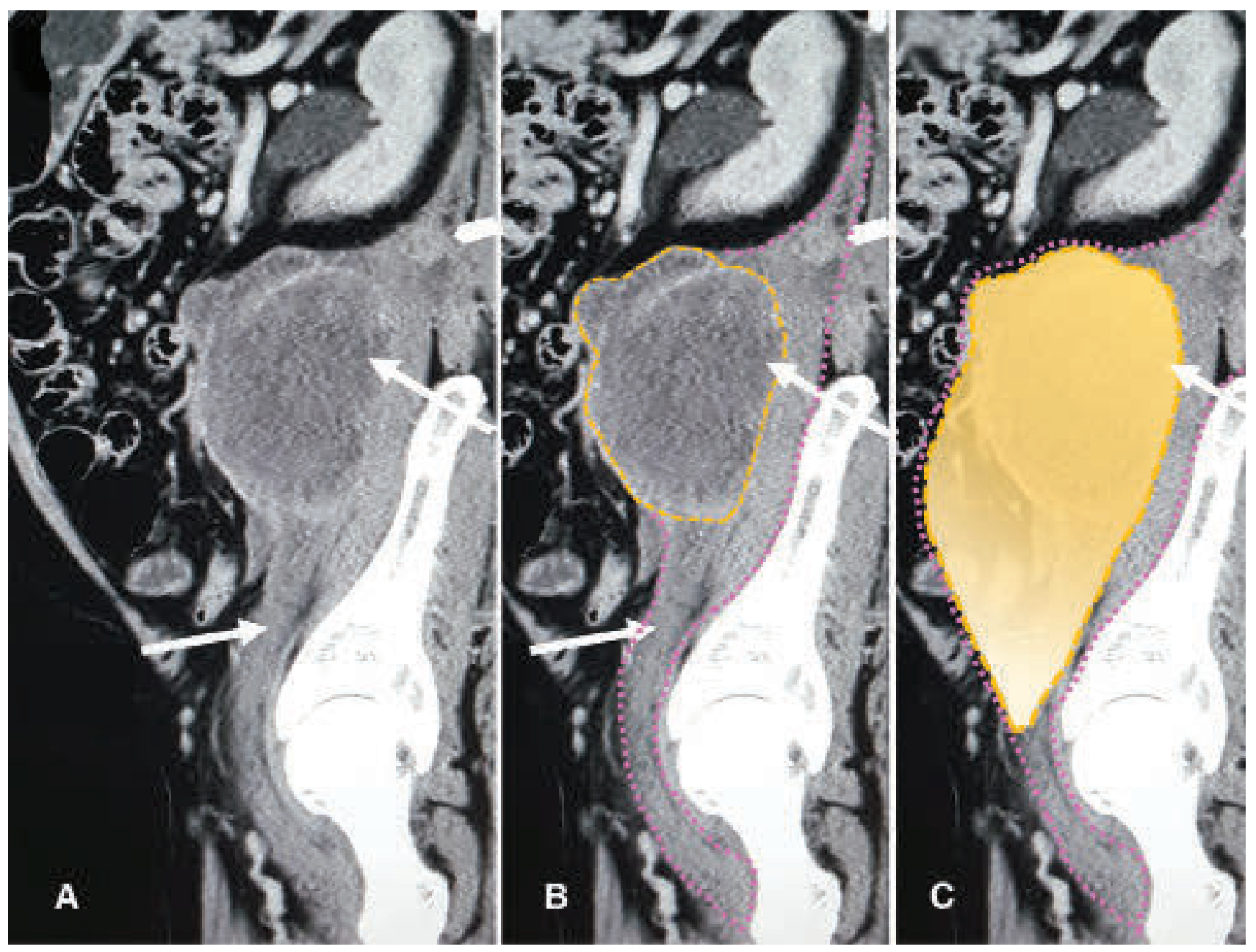

Fig. 20 Sagittal oblique CT reconstruction in the delayed venous phase. (A, B) Mass (outlined in orange) located focally within the mid belly of the psoas (outlined in pink). The distal belly and tendon of psoas are uninvolved. The satellite nodule in the adjacent psoas is marked by the arrowhead. (C) Diagrammatic representation of the behavior of a mass arising within the psoas space that would diffusely involve the psoas muscle (orange filled in space) rather than remain tethered to the ureter.
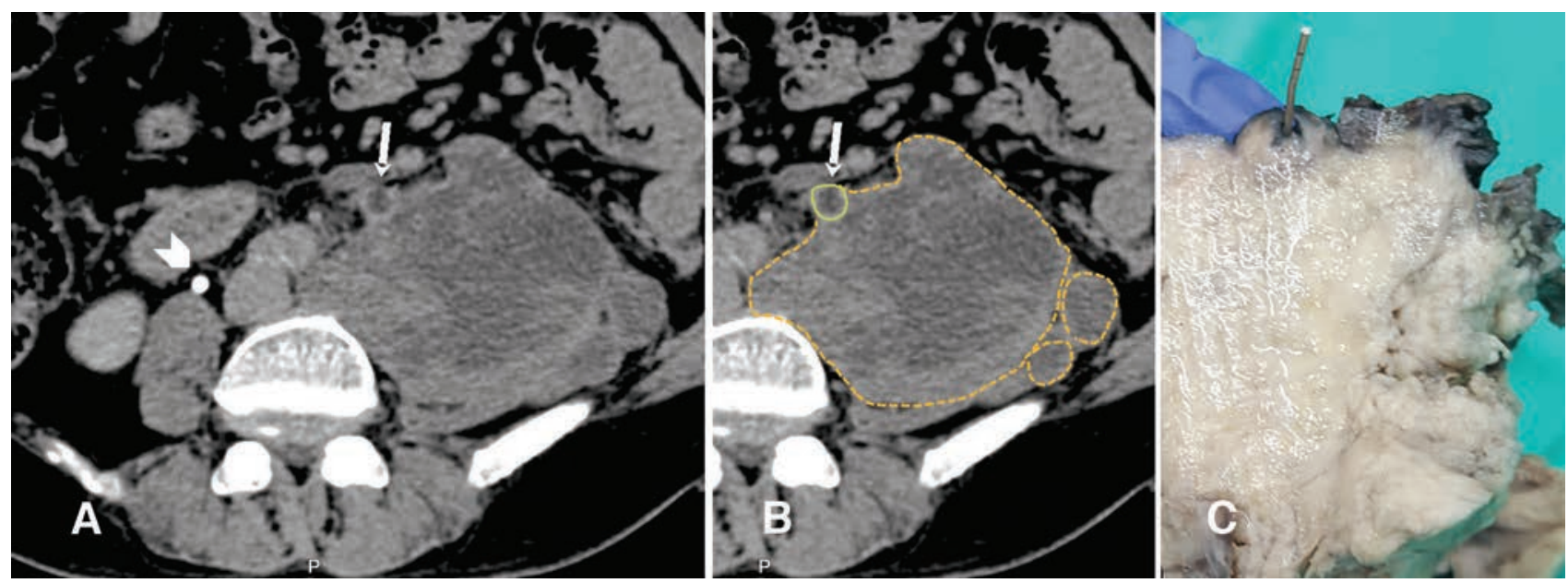

Fig. 21 (A, B) Axial CT images in the delayed phase. The left ureter is marked by an arrow and outlined in yellow. The mass entrapping the ureter is outlined in orange. (C) Corresponding sectioned gross pathology image with a thin metallic marker inserted into the lumen of the ureter.

on fat-suppressed images on MRI. These immediately raise the suspicion of a liposarcoma (LPS). Though benign masses such as lipoma and angiomyolipoma also contain fat, a homogeneous and well-defined mass comprising entirely of fat is likely to be a lipoma. A heterogeneous mass containing significantly enhancing components and closely related 
to the kidney would likely be an angiomyolipoma. Teratoma also contains fat, and mature teratoma can have fluid, fatfluid levels, and calcifications. ${ }^{16}$ Lesions that contain fluid may be abscesses, largely necrotic tumors such as LMS or lymphangioma containing spaces filled with lymph.

LPS is most common (63\%) of the primary retroperitoneal sarcomas. They appear heterogeneous and may have ill-defined margins. They are further divided into four different subtypes of well-differentiated, de-differentiated, myxoid round cell, and pleomorphic. The last three categories may not contain fat and may be mistaken for other sarcomas. Myxoid LPS appears heterogeneous and low density, with attenuation less than that of muscle on CT. Homogeneous distribution of fat and soft tissue within the mass may result in a "pseudocystic" appearance. It appears hypointense on T1W images and hyper on T2-weighted images because of the mucopolysaccharide contents in the myxoid matrix. Lacy, linear, or amorphous areas of high signal intensity on T1-weighted images and intermediate signal intensity on T2-weighted images may be seen because of the intratumoral fat content. Delayed progressive, reticular contrast enhancement due to the solid components helps differentiation from a cyst. A homogeneously hypodense mass at $\mathrm{CT}$ that has a solid appearance at US is consistent with a myxoid tumor. ${ }^{17} \mathrm{LMS}$ is the second most common (19\%) retroperitoneal sarcoma and commonly consists of sarcoma of the inferior vena cava, renal vein, and gonadal vessels. ${ }^{7}$ In the retroperitoneum, LMS tend to develop massive cystic degeneration and have central necrosis more commonly than other sarcomas. Fat and calcifications are not typically present. ${ }^{18}$ Other less frequent sarcomas include fibrosarcoma, extraosseous Ewing's sarcoma, and rhabdomyosarcoma. Other soft tissue tumors such as solitary fibrous tumor (SFT) and peripheral nerve sheath tumor (PNST) are also known in the retroperitoneum. ${ }^{7}$ SFT are rare solid large well-circumscribed vascular tumors with prominent feeding vessels. They enhance intensely in the arterial phase and retain their enhancement in the delayed phase due to their fibrous nature. Benign and malignant PNSTs are predominantly solid and may have small areas of necrosis. Benign tumors such as neurofibromas and schwannomas have smooth margins whereas malignant have infiltrative margins. Synovial sarcoma typically has cystic looking elements and can be mistaken for either abscess or haematoma. ${ }^{4}$ Malignant fibrous histiocytomas, now known as undifferentiated pleomorphic sarcoma, may grow to large sizes and have areas of necrosis and peripheral calcification. Sarcomas may arise from retroperitoneal organs such as gastrointestinal stromal tumor, uterine LMS, paratesticular/ spermatic cord, or prostatic sarcoma, and appear as heterogenous soft tissue masses. Primitive neuroectodermal tumors are a rare category of retroperitoneal soft tumors that appear heterogeneous with central necrosis and may have infiltrative margins. ${ }^{19}$ Lymphoma presents as a homogeneously and moderate to significantly enhancing solid mass diffusely extending along structures with sharply defined margins. Paragangliomas are usually well-circumscribed, large, heterogeneous, and highly vascular neoplasms arising alongside the sympathetic chain and para-aortic in location in the retroperitoneum. They show intense enhancement and are heterogeneously hyperintense on T2W MRI. ${ }^{20}$

Approximately $70 \%$ of tumors involving the ureter primarily affect its distal segment, and an overwhelming majority are TCCs. Characterization of ureteric disease can be challenging on imaging. On MDCT tumors may appear as intraluminal filling defects or wall thickening. Filling defects in the lumen of the ureter are not typical for transitional cell tumors and may also be caused by fibroepithelial polyp, inverting papilloma, and mesenchymal tumors. Thickening of the wall of the ureter may also be due to a variety of other conditions, including metastases, lymphoma, malakoplakia, radiation fibrosis, tuberculosis, schistosomiasis, endometriosis, and amyloidosis. ${ }^{21}$ TCC of the ureter can also present as a retroperitoneal mass. Cheong et al reported a case of ureteral TCC manifesting as a retroperitoneal tumor due to exophytic growth. Whereas in our case the main mass was eccentric to

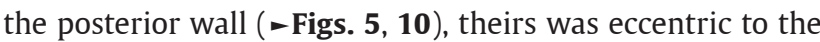
anterior wall, and the posterior ureteric wall was not invaded by the tumor. Their preoperative impressions were primary retroperitoneal malignant tumor, such as LMS, malignant fibrous histiocytoma, or LPS. However, the pathological diagnosis was an eccentric ureteral TCC that penetrated the anterior ureteral wall to form an exophytic anterior periureteric mass. In our case, our imaging diagnosis was of a TCC whereas pathological conclusion was that of a high-grade LMS. Cheong et al recommended that an exophytic TCC should be included in the differential diagnosis of a large retroperitoneal tumor, especially when a retroperitoneal mass is combined with an intraluminal ureteral soft tissue lesion and proximal and/or distal ureteral wall thickening. ${ }^{22}$ However, the mass in their case did not show significant necrosis and was half the size of the mass in our case. A large predominantly necrotic mass related to the ureter with peripheral poorly enhancing solid components is more likely to be an LMS than a TCC.

\section{Characterization of Retroperitoneal Masses by Behavior}

Our case had several enlarged heterogeneously enhancing nodes in the distribution of the lymphatic drainage of the ureter (Figs. 4A, 6A). Though Fong et al estimated lymph node metastasis from retroperitoneal sarcomas at 5 to $15 \%,{ }^{23}$ it is known that sarcomas almost never spread to lymph nodes, with the rare exception of epithelioid sarcomas, rhabdomyosarcomas, and clear cell sarcoma. Therefore, the presence of lymph nodes should raise the possibility of an alternative diagnosis such as carcinoma or lymphoma. ${ }^{4}$ TCC of the ureter often metastasizes to the regional lymph nodes. It is thought that the rich lymphatic network of the ureter ( $\mathbf{- F i g . ~ 2 2 )}$ is invaded by tumor early in its course and ureteral obstruction leads to an enhanced lymphatic flow, a factor leading to lymphatic metastases. ${ }^{24}$ The largely necrotic appearance of the mass and heterogeneity of the nodes ruled out lymphoma, leading us to erroneously believe that this was a TCC. However, the poorly differentiated nature and high grade of the mass on pathology and immunohistochemistry may explain the reason for this LMS to have not only nodal metastases but also satellite deposits in the adjacent psoas 


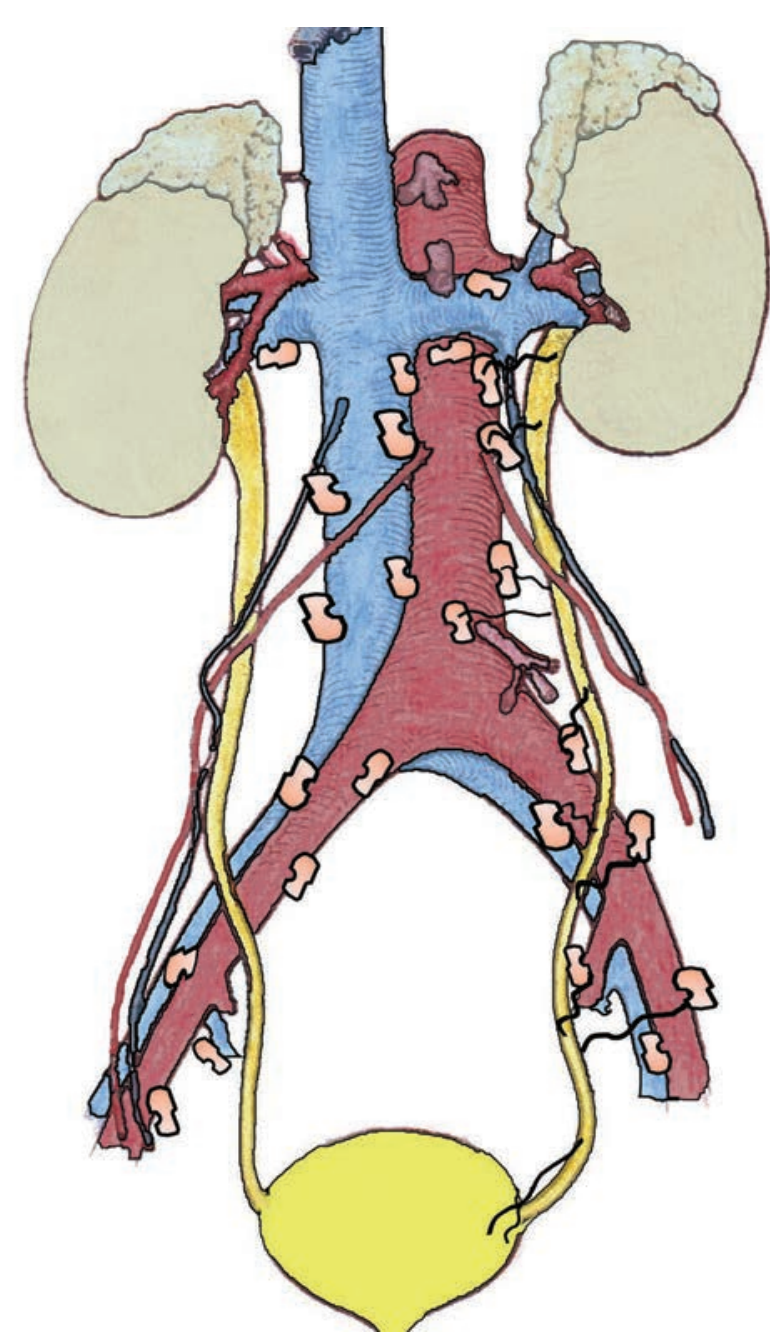

Fig. 22 Diagrammatic representation of the rich lymphatic drainage of the ureter.

muscle. The infiltrative growth pattern in our case also led us to wrongly conclude that this was a TCC as the growth pattern of retroperitoneal sarcomas is not known to be infiltrative by nature. They are known to usually grow by direct local extension into adjacent tissues and structures, often pushing them aside and less commonly invading the fascial planes, joints, or bone. ${ }^{7}$ This is why they can grow to very large masses of more than $10 \mathrm{~cm}$ before they cause symptoms. ${ }^{17}$ We erroneously concluded that because the ureter in our case was not displaced and instead was involved circumferentially, a TCC was more likely. We also erroneously interpreted the growth of the tumor within muscle coat of the ureteric wall as intraluminal extension (-Figs. 6, 12). Intraluminal extension would appear polypoidal with urine surrounding the tumor, whereas here the wall was circumferentially thickened with no clear polypoid projection. However, a TCC may also present with wall thickening without an intraluminal component, ${ }^{21}$ and a primary LMS of the ureter may extend both intra- and extraluminally. ${ }^{8}$

\section{Conclusion}

We have presented here a rare case of a primary left ureteric LMS. A step-by-step approach to arriving at the diagnosis on MDCT has been demonstrated. The combination of a tethered appearance of the mass to the ureter, its lack of diffuse extension along the psoas space, and its growth for a short length along the wall of the ureter cranial to the upper margin of the mass as well as spread to regional nodes draining the ureter were used to correctly diagnose the structure of origin as the ureter. However, its intramural growth was mistaken as intraluminal growth, and a tumor arising from the mucosa rather than the muscular layer of the ureter was erroneously made based on this. The tumor metastasized to regional nodes draining the ureter as well as made satellite nodules to the adjacent parts of the psoas muscle. This behavior was likely due to the poorly differentiated and high-grade nature of the tumor and was mistaken to be the behavior of a carcinoma with the erroneous conclusion of a TCC. A large necrotic tumor tethered to the wall of the ureter, despite being in the psoas space, with lymph nodal spread likely being a highgrade primary LMS of the ureter rather than TCC.

\section{Funding \\ None. \\ Conflict of Interest \\ None.}

\section{References}

1 Ishikawa K, Nakao S, Nakamuro M, Huang TP, Nakano H. The retroperitoneal interfascial planes: current overview and future perspectives. Acute Med Surg 2016;3(3):219-229

2 Coffin A, Boulay-Coletta I, Sebbag-Sfez D, Zins M. Radioanatomy of the retroperitoneal space. Diagn Interv Imaging 2015;96(2):171-186

3 Lenchik L, Dovgan DJ, Kier R. CT of the iliopsoas compartment: value in differentiating tumor, abscess, and hematoma. AJR Am J Roentgenol 1994;162(1):83-86

4 Messiou C, Moskovic E, Vanel D, et al. Primary retroperitoneal soft tissue sarcoma: imaging appearances, pitfalls and diagnostic algorithm. Eur J Surg Oncol 2017;43(7):1191-1198

5 Behranwala KA, A'Hern R, Thomas JM. Primary malignant tumors of the iliopsoas compartment. J Surg Oncol 2004;86(2):78-83

6 Gopalakrishnan KC. Natural "barriers" its relevance to the spread of bone sarcoma. J Bone Soft Tissue Tumors 2015;1(2):5-9

7 Gladdy RA, Gupta A, Catton CN. Retroperitoneal sarcoma: fact, opinion, and controversy. Surg Oncol Clin N Am 2016;25(4):697-711

8 Griffin JH, Waters WB. Primary leiomyosarcoma of the ureter. J Surg Oncol 1996;62(2):148-152

9 Lin WR, Yang S, Lo KY, Chang KM. Primary leiomyosarcoma of the ureter. 中華民國泌尿科醫學會雜誌 2000 Sep $1 ; 11(3): 138-41$

10 Shirotake S, Sumitomo M, Asakuma J, Asano T, Aiko S, Hayakawa M. [A case of primary leiomyosarcoma of the ureter] [in Japanese] Hinyokika Kiyo 2006;52(1):41-45 
11 Cho KH, HyunJH, Chung HY, Chang YS, Han DS. Primary leiomyosarcoma of the ureter. Korean J Urol 2007;48(11):1174-1178

12 Lv C, Chen N, Zhu X, Zhang X, Zhong Z. Primary leiomyosarcoma of the ureter. Asian J Surg 2008;31(4):191-194

13 Aubert E, Millet I, Serre I, Taourel P. Leiomyosarcoma of the ureter: a rare case. Diagn Interv Imaging 2012;93(1):60-63

14 Shastri RK. Primary leiomyosarcoma of the ureter, a case report. IOSR Journal of Dental and Medical Sciences (IOSRJDMS) 2016;15(5, Ver. VIII):59-63

15 Busuttil G, Bonello F, Mattocks S. Leiomyosarcoma of the distal ureter: a case report. Malta Med J 2016;28(4):55-57

16 Minami M, Ohmoto K, Charnsangavej C, Kawauchi N, Itai Y, Sasaki S. Origin of abdominal tumors: useful findings and signs on tomographic imaging. (abstr) Radiology 1996;201(P):491

17 Rajiah P, Sinha R, Cuevas C, Dubinsky TJ, Bush WH Jr, Kolokythas O. Imaging of uncommon retroperitoneal masses. Radiographics 2011;31(4):949-976

18 Nishino M, Hayakawa K, Minami M, Yamamoto A, Ueda H, Takasu K. Primary retroperitoneal neoplasms: CT and MR imaging findings with anatomic and pathologic diagnostic clues. Radiographics 2003;23(1):45-57
19 Kim MS, Kim B, Park CS, et al. Radiologic findings of peripheral primitive neuroectodermal tumor arising in the retroperitoneum. AJR Am J Roentgenol 2006;186(4):1125-1132

20 Brennan C, Kajal D, Khalili K, Ghai S. Solid malignant retroperitoneal masses-a pictorial review. Insights Imaging 2014;5(1):53-65

21 Atasoy C, Yağci C, Fitoz S, Sancak T, Akyar G, Akyar S. Crosssectional imaging in ureter tumors: findings and staging accuracy of various modalities. Clin Imaging 2001;25(3):197-202

22 Cheong IJ, Cha SH, Cha SH, Kim SH, Kim DS, Kim AR. Exophytic growth of ureteral transitional cell carcinoma as a cause of retroperitoneal tumor: a case report. J Korean Radiol Soc 2000;43(1):87-89

23 Fong Y, Coit DG, Woodruff JM, Brennan MF. Lymph node metastasis from soft tissue sarcoma in adults. Analysis of data from a prospective database of 1772 sarcoma patients. Ann Surg 1993;217(1):72-77

24 Winalski CS, Lipman JC, Tumeh SS. Ureteral neoplasms. Radiographics 1990;10(2):271-283 